\title{
Atividade de escrita colaborativa: percepção de alunos, princípio cooperativo de Grice e social loafing'
}

Patricia Zeni Marchiorill

Ana Carolina Greef"

I- As autoras agradecem aos alunos que colaboraram com a investigação. II- Universidade Federal do Paraná, Curitiba, PR, Brasil.

Contatos: pzeni@ufpr.br;

ac.greef@gmail.com

\section{Resumo}

Este artigo discute a efetividade das adaptações de critérios aplicados às categorias do princípio cooperativo de Grice e a possível ocorrência de social loafing em atividades de escrita colaborativa. Apresenta a concepção de uma atividade desenvolvida em editor wiki de um Ambiente Virtual de Aprendizagem (AVA), e as estratégias de envolvimento e sua aplicação junto a duas turmas de alunos de curso superior na área de ciências sociais aplicadas. Analisa os dados e os depoimentos relativos às dificuldades no domínio do editor, a clareza dos critérios de avaliação e a contribuição da experiência ao entendimento de um conceito de trabalho colaborativo. Os resultados da investigação demonstraram indícios de social loafing e de outras perdas de processo e, quanto à efetividade da aplicação dos critérios agregados às categorias do princípio de Grice, verificou-se que esses são efetivos para as contribuições individuais, mas não contemplam sutilezas e dimensões relativas às atividades em colaboração. Conclui-se que a proposta de colaboração não é uma barreira per se, ainda que dificuldades técnicas desestimulem os participantes. Um editor colaborativo que desconsidere a integração imediata entre os envolvidos gera contribuições estanques e acarreta o uso de alternativas externas ao ambiente de trabalho, o que dilui a proposta cooperativa. A divisão das tarefas, as responsabilidades de administração das páginas do editor e a definição de regras para intervenções devem ser explicitadas para que todos os envolvidos estejam seguros e motivados quanto às condições de sua participação. Ao fazer isso, diminuem-se perdas de processo e aumenta-se a efetividade de resposta aos objetivos da experiência de ensino-aprendizagem.

\section{Palavras-chave}

Trabalho colaborativo - Aprendizagem - Perdas de processo Ambiente colaborativo de aprendizagem. 


\section{Collaborative writing activity: perception of students, Grice's cooperative principle and social loafing'}

Patricia Zeni Marchioril"

Ana Carolina Greef"

I- The authors thank the students who cooperated with the investigation. II- Universidade Federal do Paraná Curitiba, PR, Brasil.

Contact:pzeni@ufpr.br;

ac.greef@gmail.com

\begin{abstract}
This article discusses the effectiveness of the adaptations of criteria applied to the categories of Grice's cooperative principle and the possible occurrence of social loafing in collaborative writing activities. It presents: the concept of an activity developed in a wiki editor of a Virtual Learning Environment (VLE); and the strategies of engagement and their application to two higher education classes in the area of applied social sciences. It analyzes data and testimonials relating to difficulties to master the editor, the clarity of evaluation criteria and the contribution of experience to the understanding of a concept of collaborative work. Research results have shown evidence of social loafing and other process losses and, as to the effectiveness of the application of the criteria added to the categories of Grice's principle, it was found that these criteria are effective for individual contributions, but do not consider subtleties and dimensions relating to activities in collaboration. It is concluded that the collaboration proposal is not a barrier per se, although technical difficulties discourage participants. A collaborative editor that disregards the immediate integration between those involved generates limited contributions and results in the use of alternatives outside the work environment, which dilutes the cooperative proposal. The division of tasks, responsibilities of managing the editor pages and setting rules for interventions should be made explicit so that all those involved are confident and motivated about the conditions of their participation. By doing so, there is a decrease in process losses and an increase in the effectiveness of responses to the objectives of the teaching-learning experience.
\end{abstract}

\section{Keywords}

Collaborative work - Learning - Process Losses - Collaborative Learning Environment 


\section{Introdução}

Considerando-se um discente de ensino superior como futuro profissional em sua especialidade, a possibilidade de se explorarem plataformas tecnológicas voltadas à geração, publicação, compartilhamento e utilização de informações se torna uma oportunidade para o aprimoramento de estilos e processos de aprendizagem próprios. Assim sendo, este trabalho parte do pressuposto segundo o qual Ambientes Virtuais de Aprendizagem (AVA) oferecem espaços de colaboração, sob a premissa de que professor e aluno se desprendem: da visão tradicional do quadro/carteira; dos papéis do docente como mantenedor e fonte exclusiva de conhecimento; do discente enquanto aprendiz estático; e do material didático produzido de forma unilateral.

Além disso, em um contexto virtual de ensino-aprendizagem, as mudanças na dinâmica das atividades presenciais e remotas modificam a concepção tradicional dos chamados trabalhos de/em grupo, que passam a ser realizados em editores colaborativos incorporados aos AVA. As wikis, por exemplo, representam uma categoria de editores que modificam o papel dos AVA - de simples repositórios de material - para instâncias de trabalho colaborativo. Um trabalho colaborativo pode ser definido como um espaço para ações conjuntas, onde os membros de um grupo se apoiam com o intuito de atingir objetivos comuns negociados pelo coletivo e estabelecem relações que se caracterizam pela ausência de hierarquia, pela liderança compartilhada, pela confıança mútua e pela corresponsabilidade quanto à condução das ações (COSTA apud DAMIANI, 2008).

Ao utilizarem ferramentas colaborativas, os indivíduos envolvidos em situações de ensino-aprendizagem têm a possibilidade de desenvolver competências transversais, entendidas como a ampliação da capacidade de raciocínio, da análise crítica, da comunicação e da condução de processos de interação (CRUZ et al., 2010). Tais aspectos apresentam desafios ao que Prata (2003) nomeou como possibilida- des de avaliação, ou seja, a conveniência do uso de testes tradicionais; a necessidade de análise da interação do usuário com o ambiente e as potencialidades das avaliações alternativas baseadas no julgamento das atividades determinadas pelo professor e desempenhadas pelo aluno. Nesse sentido, a prática e a avaliação da escrita colaborativa - definida como o processo de duas ou mais pessoas trabalhando em conjunto para criar um documento complexo (SKAF-MOLLI et al., 2007) - devem considerar: a quantidade de participações/intervenções dos participantes; as reações do grupo frente às contribuições individuais; o julgamento de relevância e originalidade; além da ponderação da dimensão individual em relação à dimensão coletiva da atividade (CRUZ et al., 2010).

Ao buscar contribuir com as investigações na temática da escrita e do trabalho colaborativo, este estudo teve como objetivo discutir a efetividade dos critérios aplicados às categorias agregadas ao princípio cooperativo de Grice, em uma atividade desenvolvida em editor wiki de um AVA. 0 princípio cooperativo de Grice pode ser conceituado, brevemente, como um conjunto de máximas (ou princípios) que sustentam uma comunicação bem-sucedida entre indivíduos (GRICE, 1989). A atividade que estimulou a interação comunicativa voltada à criação de um trabalho colaborativo foi realizada por duas turmas de alunos de uma disciplina de curso superior na área de ciências sociais aplicadas.

Antecipou-se que a atividade revelaria perdas de processo entre os participantes. Tais perdas, chamadas de perdas de motivação ou perdas de coordenação, estão associadas ao social loafing e ao chamado efeito Ringelmann, descritos como a tendência de redução de produtividade das pessoas quando essas trabalham em conjunto com outras (STEINER apud KARAU; WILLIAMS, 1993). Latentes ou explícitas, essas perdas podem existir em um ambiente de colaboração não presencial, o que reforça esse comportamento ser independente de um determinado ambiente e/ou tipo de atividade em grupo (STEINER apud FORSYTH, 2010). 
No caso específico de um editor wiki, Trentin (2008) destaca que professores encontram nesses editores não só dificuldades de avaliar a aprendizagem em si enquanto produto do processo, mas também de mensurar os distintos graus de participação e contribuição para o trabalho realizado em conjunto.

Considerando o objetivo geral do estudo proposto, sintetizaram-se quatro questões de pesquisa, que foram analisadas durante $o$ processo: 1) em que medida as categorias agregadas ao princípio cooperativo de Grice são adequadas para um trabalho colaborativo em editor wiki?; 2) distintos graus de dificuldade no domínio do editor wiki afetam o desempenho da tarefa?; 3) independentemente das dificuldades de domínio técnico, há elementos que indicam perdas de processo em um trabalho colaborativo on-line?; e 4) a experiência com o editor wiki resulta na percepção do conceito de trabalho colaborativo?

Em todo o transcorrer da pesquisa, assumiram-se como válidos os componentes individuais e coletivos da atividade, reconhecendo-se que os próprios alunos atuam na autoavaliação e na avaliação dos colegas enquanto interagem organicamente com conteúdo elaborado por eles mesmos e por terceiros.

\section{Referencial teórico}

0 processo de construção de um texto de forma conjunta não é prerrogativa de ferramentas colaborativas em rede per se. SkafMollin et al. (2007) destacam que, normalmente, o uso de um editor de texto simples e até mesmo do e-mail tem servido a esse propósito, caracterizando um processo assíncrono e não linear que exige um cuidadoso planejamento. Assim sendo, o texto elaborado em conjunto pode ser segmentado durante sua composição, o que demanda um trabalho posterior de integração de conteúdo que é, mais uma vez, manual e assíncrono. Essa condição se torna mais complexa devido à própria proposta de criação de um texto decomposto em diferentes segmentos de conteúdo. 0 desafio então é garantir um resultado íntegro e que demonstre os esforços efetivamente cooperativos e construtivos utilizados para sua composição.

Um AVA que, potencialmente, favorece tais esforços se apoia, conforme Valente, Moreira e Dias (2009), em quatro conceitos principais: 1) o construtivismo, enquanto espaço para a construção ativa do conhecimento; 2) o construcionismo, ou seja, a possibilidade de aprendizagem, a partir da construção de algo, para que terceiros experimentem esse algo; 3) o construtivismo social, enquanto reforço da cultura da criação de artefatos partilhados com significados também partilhados; e 4) o comportamento conectado e separado, enquanto espaço para a motivação individual em uma discussão.

Para cumprir tais conceitos, as funcionalidades comuns em um AVA, tais como o fórum, o chat, a enquete, um editor wiki, entre outras, devem estar a serviço de uma proposta pedagógica o mais clara possível. Contudo, ainda que as propostas didáticas venham paulatinamente reforçar a ênfase no processo e não no produto, a construção de conteúdo em colaboração via um editor colaborativo (nesse caso, um editor wiki), demanda um "[...] processo contínuo de exposição de ideias, de negociações, de argumentação" (FERRAZ, 2009, p. 151), que pode ser estimulado pela problematização e exige respeito às diferenças entre os integrantes do grupo para que suas intervenções auxiliem na execução do objetivo e na realização das metas propostas para cada atividade.

Nesse contexto, a coautoria passa a ser uma realidade desafiadora, pois distintamente do trabalho em grupo tradicional, os movimentos de postagens, ajustes, correções, inserções são visualizados tanto pelos colegas como pelo professor e eventual tutor. Há, ainda, desafios técnicos na criação de páginas, na definição de links de hipertexto internos e externos ao editor, na inserção de imagens, por exemplo. Mesmo que se criem grupos pequenos por afinidade, e que a construção coletiva de um texto não seja totalmente desconhecida pelos discentes, 
[...] os alunos, de maneira geral, encontram grandes dificuldades em produzir coletivamente, considerando que não fomos educados para isso. Tal dificuldade se apresenta na produção do texto que assume muitas vezes a forma de uma colcha de retalhos, já que os alunos tendem a incluir parágrafos sem efetivar o elo de ligação entre eles, não se sentem à vontade para interferir no texto do outro e quando o fazem podem melindrar o colega que postou a mensagem inicial (ALVES, 2009, p. 199).

Comparativamente às trocas assíncronas de arquivos por e-mail, um editor wiki potencializa o compartilhamento instantâneo e multiusuário, o que torna a tarefa menos trabalhosa e mais estimulante. Todavia, o que é uma característica positiva do editor, ou seja, sua estrutura cópia/modificação/integração (copymodifiy-merge), pode acarretar modificações cegas. Nesse caso, a interferência de um colaborador no texto impede que conteúdo esteja disponível simultaneamente para os demais integrantes do grupo (SKAF-MOLLIN et al., 2007). Apenas quando do salvamento dos respectivos textos é possível verificar demais contribuições e, eventualmente, são necessárias intervenções extras para garantir a coesão do conteúdo. Além disso, a atividade em grupo, independentemente da tecnologia disponível, não é isenta de percepções individuais sobre a atividade coletiva e dos esforços aí concentrados.

\section{As perdas de processo/ motivação na atividade em grupo}

A princípio, ferramentas para escrita e trabalho colaborativo tendem a facilitar uma construção em grupo. Contudo, Harkins e Szymanski (1989) analisam e explicam os efeitos das perdas de processo/motivação para esse tipo de atividade sob três mecanismos psicossociais, a saber: a) o free-riding, em que o indivíduo não participa dos esforços, mas usufrui dos benefícios;

b) o sucker effect, no qual um participante verifica que outros estão se aproveitando de seu trabalho; e

c) o social loafing, que se refere à redução do esforço exercido quando se trabalha em grupo em relação ao que realizaria de forma individual.

Experimentos que investigam tais mecanismos remontam ao início do século XX, como resposta e explicação ao decréscimo de desempenho em trabalhos/esforços que envolviam grupos de pessoas. Steiner (1972, apud KARAU; WILLIAMS, 1993) identificou a perda de motivação e a perda de coordenação como causas do social loafing. Ambas são, segundo Forsyth (2010), fatores também associados ao chamado efeito Ringelmann (inatividade social). Primeiramente documentado por Max Ringelmann em 1913, o efeito que leva seu nome designa a tendência à redução da produtividade das pessoas quando trabalham com outras, sendo que essa perda aumenta conforme o tamanho do grupo em proporção direta.

Entre as conclusões de um estudo que comparou estudantes de uma universidade e alunos de uma escola militar naval, Piezon e Ferree (2008) destacam que o social loafing está relacionado com seis fatores: a) as influências existentes no grupo; b) o desempenho do processo realizado pelo grupo; c) o tipo de tarefa a ser efetivada; d) o tamanho do grupo; e) a influência administrativa dos orientadores/supervisores; e f) as percepções individuais.

Para os autores, o desempenho do grupo só será efetivo se seus membros puderem trafegar de forma consistente em cada um dos seis parâmetros. Harkins e Szymanski (1989) propõem, como uma forma de amenizar o social loafing, a identificação e mensuração transparente e unívoca da contribuição de cada membro, além da definição de um padrão único no qual todos os aportes à atividade são comparáveis em termos de sua efetividade. Nesse caso, a avaliação das contribuições individuais no grupo e vice-versa tem papel crítico. 


\section{As categorias agregadas ao princípio cooperativo de Grice e a avaliação da atividade colaborativa em ambiente virtual}

Cruz et al. (2010) discutem distintas funções da avaliação, destacando-a como parte intrínseca do aprendizado, na qual o aluno é um componente crítico e central na elaboração não de um produto final, mas de um processo que deve pressupor e estimular a autoavaliação apoiada na reflexão e em efetivas correções nas tarefas desempenhadas. Os ambientes on-line predispõem a interatividade e a colaboração, extrapolando a avaliação da dimensão individual para componentes da construção de conhecimento coletivo. Vários exemplos de estudos voltados para a aprendizagem colaborativa são listados por Swan, Shen e Hiltz (2006), que alertam para dificuldades no desenvolvimento de uma metodologia consistente para o julgamento de valor e consequente avaliação das atividades. Para as autoras, tal processo avaliativo envolve pelo menos três aspectos: 1) a diversidade de objetivos para a colaboração on-line; 2) a complexidade no julgamento de comportamentos individuais relativos tanto ao indivíduo no grupo como ao próprio grupo; e 3) a colaboração dos alunos no dimensionamento da atividade e na proposta de avaliação.

Em se tratando da construção de conhecimento coletivo, o presente estudo se apropria da contribuição de Paul Grice (1989), relativa a um tipo de lógica estruturante que envolve a interpretação de mensagens informais e conversações casuais. Grice, ao criar a expressão implicaturas conversacionais (conversational implicatures), caracterizou os tipos de inferências que permitem aos interlocutores interpretar comentários de terceiros sem o uso das regras da lógica formal fora das quais a conversação se torna insustentável. As implicaturas se relacionam com o que o autor chama de princípio cooperativo (cooperative principle), assim formulado:

Make your conversational contribution such as is required, at the stage at which it occurs, by the accepted purpose or direction of the talk exchange in which you are engaged (GRICE, 1989, p. 26).

A esse princípio, o autor agregou quatro categorias principais (categorias conversacionais), a partir das quais definiu supermáximas, máximas e submáximas que sustentam uma conversação bem-sucedida, conforme demonstra o quadro 1, abaixo:

Quadro 1 - Princípio cooperativo de Grice: categorias, supermáximas, máximas e submáximas

\begin{tabular}{c|ccc}
\hline Quantidade & Faça sua contribuição o mais informativa possível (tendo um propósito de troca) & Máxima \\
\hline Nualidade & Fão faça sua contribuição mais informativa do que o necessário & Máxima \\
\hline Relevância & Não diga nada que acredite ser falso & Supermáxima \\
\hline & Não diga o que carece de evidência & Máxima \\
\hline Modo & Contribuição relevante & Máxima \\
\hline & Seja claro & Supermáxima \\
\hline & Seja breve (evite a proxilidade desnecessária) & Supermáxima \\
\hline & Seja ordenado & Máxima \\
\hline
\end{tabular}

Fonte: traduzido pelas autoras, com adaptações, de Grice (1989). 
Ao discutir as interpretações conflitivas que derivam da aplicação da teoria de Grice, Davies (2007) explora o uso da palavra cooperativo no campo da linguística, no qual se pressupõe que há uma expectativa de interação como resultado de um comportamento humano positivo e proativo na atividade de conversação. 0 autor defende que, mesmo não intencional ou conscientemente, podem surgir relações ambíguas na emissão de uma mensagem, ainda que essa respeite uma estrutura racional que favoreça o diálogo de forma efetiva.

Uma abordagem anterior do tema, feita por Forman e Larreamendy-Joerns (1998), considera que as categorias agregadas ao princípio cooperativo de Grice são válidas tanto para a conversação diária/informal como para o discurso científico. Porém, afırma que há diferenças relativas ao grau e tipo de responsabilidade que pode ser atribuído aos participantes do processo, ou seja, às expectativas quanto às ações e desempenho desses em trocas comunicativas. Assim, quanto mais próximo do discurso científico, normalmente pautado por normas rígidas de expressão, em especial na construção de um texto acadêmico, menor será a espontaneidade dos participantes.

Para que tais categorias e componentes pudessem ser utilizados como critérios em um trabalho colaborativo, assumiu-se a adaptação de Ho e de Swan (2007), Shen e Hiltz (2006). Esses autores expandiram a escala de avaliação de Pelz (2004) - a qual atribuía originalmente quatro pontos positivos, uma posição neutra e duas pontuações negativas (retirada de pontos proporcional ao desvio do tópico/ tema considerado relevante) -, resultando na pontuação das categorias conversacionais agregadas ao princípio cooperativo de Grice, como demonstra o próximo quadro.

Quadro 2 - Pontuação atribuída às categorias do princípio cooperativo de Grice

\begin{tabular}{|c|c|c|c|c|}
\hline [Pontos] & Quantidade & Qualidade & Relevância & Modo \\
\hline 3 & $\begin{array}{l}\text { A quantidade de informa- } \\
\text { ção é suficiente para se } \\
\text { compreender a finalidade } \\
\text { da postagem }\end{array}$ & $\begin{array}{l}\text { A postagem é uma nova contribuição } \\
\text { (ex.: novidade, originalidade), que reflete } \\
\text { as opiniões do aluno, e é suportada por } \\
\text { evidências / exemplos confiáveis }\end{array}$ & $\begin{array}{l}\text { A postagem relaciona- } \\
\text {-se ao tópico [da confe- } \\
\text { rência] e da postagem } \\
\text { anterior }\end{array}$ & $\begin{array}{l}\text { A informação está logicamente or- } \\
\text { ganizada e não apresenta erros de } \\
\text { ortografia, pontuação, gramática; } \\
\text { o significado da postagem é clara- } \\
\text { mente apresentado }\end{array}$ \\
\hline 2 & $\begin{array}{l}\text { Há indícios de informação } \\
\text { em excesso ou ausência } \\
\text { de informação; ainda as- } \\
\text { sim, a finalidade da posta- } \\
\text { gem é razoavelmente clara }\end{array}$ & $\begin{array}{l}\text { (a) A postagem é uma nova contribui- } \\
\text { ção que reflete as opiniões do estu- } \\
\text { dante; ainda assim, não são inseridos } \\
\text { exemplos / evidências que sustentem } \\
\text { os argumentos; ou } \\
\text { (b) A postagem reflete a opinião do } \\
\text { estudante e são oferecidos exemplos / } \\
\text { evidências confiáves }\end{array}$ & $\begin{array}{l}\text { A postagem relaciona- } \\
\text { se com } 0 \text { tópico [da } \\
\text { conferência], mas não } \\
\text { com a postagem anterior }\end{array}$ & $\begin{array}{l}\text { A postagem está adequadamente } \\
\text { organizada; se algum erro é encon- } \\
\text { trado, não é severo o suficiente para } \\
\text { prejudicar o significado }\end{array}$ \\
\hline 1 & $\begin{array}{l}\text { Há um excesso ou ca- } \\
\text { rência de informação de } \\
\text { forma que o propósito da } \\
\text { postagem é, ocasional- } \\
\text { mente, obscuro }\end{array}$ & $\begin{array}{l}\text { (a) A postagem representa as opiniões } \\
\text { do estudante, ainda que os exemplos } \\
\text { / evidências não oferecem suporte aos } \\
\text { argumentos; ou } \\
\text { (b) A postagem é uma reconfiguração } \\
\text { de postagens anteriores, mas incorpora } \\
\text { novas contribuições com caráter menor }\end{array}$ & $\begin{array}{l}\text { A postagem é sobre } \\
\text { mesmo tópico ou de } \\
\text { qualquer outra postagem } \\
\text { anterior, mas não sobre } \\
\text { [a conferência] }\end{array}$ & $\begin{array}{l}0 \text { aspecto técnico da postagem (ex.: } \\
\text { organização, ortografia, gramática) } \\
\text { apresenta vários problemas, os } \\
\text { quais obscurecem, ocasionalmente, } \\
\text { o significado }\end{array}$ \\
\hline 0 & $\begin{array}{l}\text { Há um expressivo exces- } \\
\text { so ou carência de infor- } \\
\text { mação que o propósito } \\
\text { da postagem não pode } \\
\text { ser compreendido }\end{array}$ & $\begin{array}{l}\text { (a) A principal ideia da postagem é uma } \\
\text { reconfiguração das postagens anteriores } \\
\text { e não há novas contribuições; ou os } \\
\text { exemplos / evidências não são confiáveis }\end{array}$ & $\begin{array}{l}\text { A postagem é irrelevante } \\
\text { tanto para o tópico [da } \\
\text { conferência] como para } \\
\text { as postagens ateriores }\end{array}$ & $\begin{array}{l}\text { A postagem é organizada de forma } \\
\text { sofrivel e/ou tem erros sérios de } \\
\text { estruturação ou uso de sentenças, } \\
\text { adicionado da dificuldade de enten- } \\
\text { dimento da postagem }\end{array}$ \\
\hline
\end{tabular}

Fonte: traduzido pelas autoras, com adaptações, de Ho e Swan (2007). 
Esse quadro de pontuação foi apresentado e discutido com os alunos antes da atividade de escrita e trabalho colaborativo, conforme o descrito no item metodologia.

\section{Metodologia}

De forma a sustentar a consecução do objetivo geral da pesquisa, foi criada uma experiência com editor wiki inserido no AVA institucional. A atividade envolveu cinco etapas, a saber:

\section{a) A proposta de atividade}

A atividade foi desenvolvida em duas turmas de alunos de uma mesma disciplina de primeiro período de um curso superior na área de ciências sociais aplicadas, sendo uma turma por semestre. Professor e tutor da disciplina adaptaram as discussões e as fases relativas à metodologia de implementação e avaliação de e-portfólios (portfólios digitais) (CRUZ et al., 2010), aplicando-as à atividade em editor colaborativo, no caso um editor wiki.

Nessa primeira etapa, definiram-se os objetivos da atividade e se preparou um tutorial para as principais funcionalidades do referido editor. 0 objetivo de aprendizagem da atividade foi estabelecido e explicitado aos discentes como sendo: identificar e discutir os conceitos basilares da ciência da informação em sua concepção histórico-epistemológica, sua contribuição ao estudo do fenômeno informação e suas relações teórico-práticas em áreas aplicadas, especialmente a gestão da informação. Esse objetivo deveria ser atingido em grupos de três a cinco alunos, mediante análise de um artigo científico selecionado pelo grupo e com apoio em três outros textos indicados pelo professor.

\section{b) Documentação da proposta}

Elaborou-se um documento guia para a atividade, o qual continha: os critérios para seleção do artigo científico por parte dos grupos; o cronograma de execução da atividade em três rodadas (um texto de apoio a cada rodada); as orientações para o uso do material de apoio; e os resultados esperados ao final do processo. Esse documento foi inserido no AVA juntamente com a pontuação aplicada às categorias do princípio cooperativo de Grice, utilizada como base de avaliação do resultado de cada rodada e da atividade como um todo.

Professor e tutor respeitaram a centralidade dos alunos que, segundo Pelz (2004), efetiva-se com a promoção de espaços que viabilizem discussões, estimulem pesquisa por recursos na web e, especialmente, favoreçam a autoavaliação Assim, foram definidas seis estratégias de envolvimento adicionais para a realimentação da tarefa, a saber:

1) discussões presenciais em horário extraclasse com tutor e, eventualmente, com o professor;

2) tutorial do uso do editor wiki (disponível no AVA);

3) fórum para discussões e apoio entre grupos;

4) abertura de espaços de chat no AVA (com agendamento prévio);

5) uma rodada de orientação presencial para as equipes; e

6) realimentação por parte do professor no espaço de cada grupo no editor wiki, sugerindo ajustes para as rodadas seguintes.

Procurou-se manter o máximo de fidelidade no encaminhamento da atividade entre ambas as turmas - primeiro e segundo semestres - sendo modificados, para a segunda turma, a data de finalização da atividade e o acesso aos trabalhos entre os grupos.

\section{c) Aplicação da atividade}

Os grupos de alunos foram criados com total autonomia pressupondo-se que um processo natural de agrupamento facilitaria a construção de laços de confiança, estimulando a discussão, a execução da atividade e, portanto, a cooperação.

Cumpriu-se o cronograma de trabalho da atividade, efetivando-se as realimentações 
nos espaços de compartilhamento/envolvimento. Os alunos, docente e tutor puderam visualizar relatórios de acesso e edição do conteúdo, listas de colaboradores, logs de entrada/saída do AVA e do editor wiki, e ações realizadas pelos participantes, os quais foram gerados automaticamente.

\section{d) Questionário de realimentação e análise da experiência}

Como suporte à etapa final da atividade, elaborou-se um questionário de realimentação na plataforma Google Docs ${ }^{T M}$ - formulários, o qual foi respondido de forma anônima, individual e voluntária pelos alunos participantes. 0 instrumento abordou:

1) a percepção dos objetivos e critérios de avaliação da atividade por parte do respondente;

2) o domínio do editor wiki e respectivas funcionalidades;

3) a(s) dinâmica(s) de trabalho utilizada(s) pelo(s) participante(s) e respectivo grupo;

4) o grau de dificuldade do uso dos textos de apoio;

5) o tempo dedicado ao trabalho; e

6) o relato pessoal da experiência de colaboração.

$\mathrm{Na}$ segunda turma, ao se verificarem inconsistências na primeira aplicação do instrumento, a redação de algumas questões foi levemente modificada visando a facilitar o entendimento.

\section{e) Condições prévias de avaliação da experiência}

A avaliação da experiência apoiou-se na leitura das postagens no editor wiki de cada grupo; nos relatórios gerais de contribuição disponíveis no editor wiki; nas respostas ao questionário; nas conversas informais com alunos; nas comparações eventuais entre ambas as turmas; e na troca de impressões entre professor e tutor. Os dados derivados dos questionários foram analisados em conjunto e complementados quando os grupos ofereceram respostas notavelmente distintas. Importante destacar que se preservou integralmente a identidade dos participantes.

\section{Discussão e análise dos resultados}

A discussão e a análise dos resultados seguem a sequência das questões de pesquisa apresentadas anteriormente e se apoiam na coleta de dados formal e informal realizada durante e após a atividade em ambas as turmas, adicionando-se, quando plausível, aportes da literatura pertinente.

De 21 alunos que iniciaram a atividade da primeira turma, 18 cumpriram todas as etapas (85,7\% do total). Na segunda turma, a atividade iniciou com 29 alunos, dos quais 24 finalizaram as três rodadas $(82,7 \%$ do total). $\mathrm{Na}$ primeira turma, dos 18 participantes que finalizaram a atividade, 14 responderam o instrumento e, na segunda turma, dos 24 participantes, 9 ofereceram retorno. Em termos percentuais, a primeira turma contribuiu com $77,7 \%$ de retorno à experiência, enquanto a segunda foi representada por apenas $37,5 \%$ do total potencial de respondentes.

\section{As categorias agregadas ao princípio cooperativo de Grice e seu uso em atividade colaborativa em editor wiki}

0 trabalho on-line assíncrono permite, potencialmente, que os participantes reflitam a respeito da contribuição de seus colegas, assim como das próprias intervenções (HO; SWAN, 2007). Questionados quanto ao uso da guia histórico do editor wiki, a qual permite a visualização de todas as postagens realizadas durante toda a atividade, os alunos apontaram em ordem decrescente de frequência: a) a visualização da sua própria versão; b) a visualização do material do(s) colega(s); e c) a visualização das intervenções do professor e/ou tutor.

Ressalta-se que os alunos da primeira turma tiveram acesso ao conteúdo elaborado pelos demais grupos em suas respectivas wikis, enquanto que na segunda turma os próprios participantes solicitaram o bloqueio dessa possibilidade por considerarem o risco de plágio. 
Apesar de tal oportunidade estar disponivel para a primeira turma, a visualização de material de outra equipe foi pouco frequente para $50 \%$ dos respondentes, sendo que apenas um participante $(7 \%)$ indicou esse uso como muito frequente.

Tais movimentos estão alinhados ao que já foi identificado por Ho e Swan (2007), sendo possivel especular que a visualização das postagens dos colegas e desses em suas próprias contribuições pode ocorrer com o objetivo de se verificar que intervenções o texto sofreu por parte dos demais colegas. Isso revela um aspecto mais ou menos sutil da autoavaliação e da avaliação da competência do parceiro no cumprimento dos objetivos da atividade (TRENTIN, 2008).

Um participante, que usou do histórico para verificar se houve modificações em suas postagens por parte dos colegas, indicou que seria interessante que o(s) colega(s) avisasse(m) das modificações realizadas. 0 histórico ainda foi utilizado, segundo outros dois depoimentos, para a cópia do modelo de estruturação do conteúdo da atividade, que havia sido disponibilizado previamente aos alunos pelo tutor, e como recurso para imprimir uma cópia de segurança do material desenvolvido. Tais ações foram justificadas, uma vez que não só o ambiente colaborativo no qual a atividade deveria ser realizada apresentou instabilidade durante o processo, como o participante considerava que sua falta de domínio do editor wiki poderia acarretar perda do material, prejudicando todo o grupo.

Contudo, para a segunda turma, ainda que a visualização da versão própria tenha sido também a mais frequente, aquela relativa às correções do professor/tutor foi, proporcionalmente, mais constante que a das postagens dos colegas. Não houve depoimentos espontâneos acerca de outros usos da guia histórico.

Os critérios de avaliação, conforme descritos no quadro 2, foram considerados compreensíveis por 57\% dos respondentes da primeira turma e 77\% da segunda, ressaltando-se que, para essa última, houve um reforço na explicação dos critérios/categorias. Os participantes que declararam ter compreensão plena dos critérios foram capazes de citá-los e incluir observações a respeito da importância da categoria qualidade que, segundo um dos alunos, "fomenta a inovação e reduz a redundância".

Em ambas as turmas, ao se avaliar a inserção de cada critério/categoria na atividade realizada pelos grupos, identificou-se que a categoria quantidade estava desvinculada das categorias qualidade e relevância. Ou seja, em um número significativo de grupos, a área de construção do texto foi acessada várias vezes por um mesmo elemento do grupo sem que esse realizasse contribuições significativas à atividade.

Postagens mais consistentes, avaliadas com pontuação mais alta para qualidade $\mathrm{e}$ relevância, efetivaram-se - no máximo e nesse caso - por dois elementos do mesmo grupo. Ainda que demais colaboradores demonstrassem maior número de acessos, tais movimentos não refletiram aportes significativos ao conteúdo final. Verificou-se que vários grupos procuraram equilibrar a divisão de postagens de forma a garantir quantidade para todos os participantes, segmentando partes dos textos de apoio ou da estrutura de trabalho para a rodada. Nesses casos, nenhum elemento do grupo se responsabilizou por uma revisão final de consistência do texto, fato que afetou as notas de todos os participantes no que se referiu à categoria modo.

A categoria modo apresentou, ainda, um denominador comum: independentemente da quantidade, qualidade e relevância das postagens, a organização da informação nivelou negativamente os participantes. Ou seja, erros gramaticais, ortográficos e de digitação permaneceram inalterados, mesmo que o texto tenha sido visualizado por vários elementos do grupo. Poder-se-ia especular, considerando-se alguns depoimentos informais, que, conforme afirma Alves (2009), os alunos não se sentiram à vontade para modificar o texto elaborado por outro componente do grupo e que, tampouco, cada componente estava confortável quanto à possibilidade/necessidade de corrigir suas próprias contribuições.

Aqueles respondentes que declararam uma compreensão parcial dos critérios de 
avaliação da atividade indicaram o uso dos textos de apoio como sendo parte do processo de avaliação, enquanto outros citaram o domínio das funcionalidades do editor wiki. Dois alunos (um em cada turma) ressaltaram como critério de avaliação a colaboração, elemento que não estava explicitado no quadro 2.

\section{Domínio do editor wiki e impactos no desempenho da atividade}

Segundo Brodahl, Hadjerrouit e Hansen (2011), a escrita e o trabalho colaborativo implicam não só ações efetivadas diretamente em um artefato (nesse caso, no editor wiki), mas também espaços de conversação. Nesse sentido, as características de edição assíncrona, de proteção da edição e a inexistência de um alerta de edição simultânea (SKAF-MOLLI et al., 2007) não só foram percebidas pelos participantes, como também apontadas por eles como fatores desmotivadores para a execução da atividade. Reconhecidas tais fragilidades técnicas e a carência de recursos de comunicação síncrona (chat, por exemplo), os alunos foram questionados acerca do uso de outras dinâmicas/ferramentas para suprir tais fragilidades e/ou melhorar a comunicação entre os membros do grupo. Nas duas turmas, os grupos afırmaram que lançaram mão de sistemas de mensagens instantâneas, serviços de chat agregados a envio de e-mail, e mensagens em redes sociais para determinar horários para postagem, assim como para encaminhar outras discussões relativas à atividade.

A pressão dos prazos de apresentação de resultados (fechamento das rodadas), os conflitos no salvamento de versões e a efetiva perda do trabalho dos colaboradores (quando ocorreram) igualmente levaram os grupos a editar material em outras ferramentas e, posteriormente, colar o resultado no espaço do editor wiki.

Uma das estratégias extras de envolvimento definida pelo tutor foi a de disponibilizar um fórum para a troca de informações entre os alunos. A participação nesse fórum seria recompensada caso houvesse uma dinâmica de solicitação de ajuda e respostas consistentes a tais solicitações. Ainda que na primeira turma esse recurso tenha sido utilizado em três ocasiões, não se consolidou como um efetivo apoio entre os alunos e grupos e, na segunda turma, nem chegou a ser utilizado.

Questionados sobre o grau de facilidade/ dificuldade de uso dos recursos do editor wiki, alunos de ambas as turmas indicaram um maior grau de facilidade na edição simples de texto e no uso do histórico, assim como na construção do sumário. A inserção de imagens e, principalmente, de tabelas foram apontadas como funcionalidades com maior grau de dificuldade. Ainda que o tutorial sobre o editor tenha sido utilizado por todos os respondentes (conforme indicações no(s) questionário(s)), o uso das funcionalidades limitou-se à simples configuração de âncoras para composição do sumário de uma única página e a criação de alguns links de hipertexto.

Quando indagados a respeito da quantidade de horas dedicadas à atividade, os resultados apresentam uma relação direta apenas no domínio, pelo participante, de alguns recursos do editor wiki. Por exemplo, um maior número de horas dedicadas resultou em menor dificuldade na elaboração do sumário. Contudo, não foi possível estabelecer uma relação direta entre o investimento de tempo e a apropriação/entendimento dos critérios de avaliação, ou mesmo do domínio de outras características do editor.

\section{0 trabalho colaborativo on-line e as perdas de processo}

Em relação à dinâmica defınida para as postagens, aproximadamente $80 \%$ dos respondentes (em ambas as turmas) indicaram que, frequentemente, dividiram as postagens entre os componentes de seu grupo. Com base nos relatórios obtidos do AVA, verificou-se que um ou dois elementos de cada grupo iniciaram as postagens, criando uma estrutura básica que foi pouco modificada pelos demais integrantes. Em parte significativa dos grupos observados, o autor da primeira postagem também encerrou o 
ciclo de contribuições e, não raras vezes, realizou ajustes de forma a melhorar a consistência do trabalho (máxima da relevância). Em outros casos, a divisão do trabalho é explícita, sendo possível perceber os diferentes estilos de redação e falta de coesão do texto como um todo.

As ações (ou inações) dos colegas de grupo também encontraram eco nos depoimentos relativos ao conceito de trabalho colaborativo. Menções à dedicação, confiança, ao entendimento do que seja um grupo e, especialmente, à responsabilidade nas intervenções/modificações no texto (e correção de contribuições de terceiros) parecem demonstrar que as relações entre os membros foram construídas durante $o$ processo. Na primeira turma, o encerramento da atividade após a prova semestral revelou-se um obstáculo para a finalização do trabalho. Enquanto alguns alunos já aprovados continuaram participando da atividade, explicitando informalmente ao professor ou ao tutor que assim o faziam para ajudar um colega cuja situação de aprovação estava pendente, em outros casos, a diminuição do nível de participação resultou em abandono da atividade na última etapa.

A visualização dos movimentos de edição/ajuste/criação de conteúdos permitiu perceber a existência de lideranças nos grupos. Possivelmente, ocorreram outros movimentos formais e/ou informais de troca de informação. Porém, como tais procedimentos não foram monitorados, assume-se essa percepção como especulativa. Um aluno da primeira turma explicitou que a organização da atividade entre os membros do grupo ocorreu totalmente fora da ferramenta. Esse relato reforça o grau de dificuldade médio, indicado em ambas as turmas, relativo à necessidade de coordenação interna do grupo para a elaboração da atividade. A dificuldade em se articular uma coordenação interna igualmente foi explicitada em respostas relativas aos procedimentos de operacionalização, colaboração e cooperação entre os elementos do grupo frente à atividade.

Efetivamente, três grupos (um da primeira turma e dois da segunda) utilizaram o espaço do editor wiki para postar recados, cronogramas e orientações para os colegas de grupo. Esses conteúdos foram apagados pelos participantes durante a sequência das versões, o que revela uma tentativa de organização interna e divisão de responsabilidades. Por outro lado, 50\% dos respondentes da segunda turma declararam ter dificuldades (em grau médio) quando solicitados a avaliar a atividade do colega, no sentido de contribuir para o aprimoramento das postagens, se comparados aos 21\% dos respondentes da primeira turma. Essa variação numérica pode indicar diferentes níveis de confiança e de efetividade na articulação entre os membros dos grupos. Um respondente destacou o sentimento de ansiedade decorrente da espera da postagem de um colega, cujo relacionamento com o restante do grupo, e consequente participação na construção do texto, foi intermitente.

\section{Percepção do trabalho colaborativo com o uso de editor wiki}

Na questão relativa ao objetivo do uso do editor wiki na atividade, alunos de ambas as turmas indicaram esse objetivo como sendo o trabalho em grupo, a colaboração em grupo e o uso de uma ferramenta da web 2.0, em detrimento do objetivo formal da atividade ${ }^{1}$. Ainda assim, houve a percepção de aspectos mais próximos ao escopo da atividade, tais como o conteúdo final do trabalho ("cientificidade da ciência da informação pela leitura e relação entre artigos da área”); a importância da participação equilibrada entre integrantes do grupo; o uso de funcionalidades do editor; e a possibilidade de correção ou análise do trabalho dos colegas.

0 questionário solicitava um depoimento final do aluno a respeito do significado que ele atribuía ao trabalho colaborativo após a experiência com o editor wiki. Alguns respondentes

1- Identificar e discutir os conceitos basilares da ciência da informação em sua concepção histórico-epistemológica, sua contribuição ao estudo do fenômeno informação e suas relações teórico-práticas em áreas aplicadas, especialmente a gestão da informação. 
reforçaram que, ainda que as postagens fossem individuais, "o sucesso do trabalho em equipe depende de todos".

Dois depoimentos sintetizaram uma percepção próxima do que poderia ser considerado ideal nesse sentido. Um mencionou a necessidade de dedicação e responsabilidade na construção de estudos a muitas mãos para entender, discutir, alterar contribuições de colegas e "construir o conhecimento da melhor forma possível". Outro conceituou trabalho colaborativo como sendo "[a] adição ou modificação progressivas de conteúdo por uma equipe que busca equilíbrio e consenso de valores de participações individuais”.

Ainda assim, algumas observações consideraram a proposta de colaboração como "incompatível com a necessidade de divisão das postagens entre integrantes do grupo", agravada pela não interatividade de alguns integrantes ou à ausência de cuidado/responsabilidade nas intervenções que modificavam o material já postado. Entre as respostas obtidas, houve ressalvas quanto à responsabilidade e seriedade esperada por parte de todos os integrantes de um grupo para o desenvolvimento de um trabalho colaborativo, o que inclui o domínio do tema em questão e a parceria entre os participantes. Um respondente declarou que seu entendimento do que seria um trabalho colaborativo foi "diferente do que aconteceu no [sic] wiki”. Argumentou que houve pouco tempo de debate para a divisão das postagens, que essas foram realizadas individualmente e que a colaboração se reduziu significativamente na terceira rodada devido à ausência/abandono de alguns integrantes do grupo.

A visualização dos conteúdos de todos os grupos pelos demais recebeu indicações positivas (foi reconhecida como estimulante) por respondentes da primeira turma. Integrantes da segunda turma declararam tal procedimento como inviável, solicitando o bloqueio dessa funcionalidade para impedir o que consideravam plágio. Poder-se-ia especular até que ponto o entendimento dos critérios de avaliação - aliado à percepção de plágio e/ou de aplicação injusta da pontuação - levou a essa solicitação que, a princípio, contrariaria uma proposta de trabalho colaborativo. Ainda assim, dois depoimentos destacaram a validade da experiência como preparação para o mercado de trabalho, que exige parcerias e domínio de ferramentas de criação de conteúdo e interação.

\section{Considerações finais}

Críticas formais e informais ao editor wiki e à instabilidade do AVA foram constantes em ambas as turmas, ainda que acompanhadas do senso de desafio dos participantes. Pode-se afirmar que o domínio das funcionalidades do editor wiki interfere diretamente no desempenho da atividade, pois respondentes se declaram inseguros na inserção de postagens, sendo impelidos a refazê-las, guardar cópias de segurança e utilizar ferramentas externas para garantir o cumprimento da tarefa.

Os mecanismos de envolvimento criados para apoiar a atividade foram ineficientes, excetuando-se os grupos presenciais de discussão com o tutor, aos quais nem todos os alunos acompanharam devido ao horário de realização. 0 fórum recebeu aportes mínimos na primeira turma e, mesmo com a indicação de premiação das intervenções, não se confirmou como um instrumento adicional para a troca de experiências e entreajuda dos grupos. Sessões de chat foram oferecidas para as turmas (desde que com um mínimo de cinco participantes) em um horário livre no mesmo turno das aulas. Apesar do interesse de alguns alunos, o número de inscrições foi insuficiente, inviabilizando a realização. Ainda assim, depoimentos solicitaram um acompanhamento mais constante e ostensivo da atividade por parte do professor e do tutor.

Devido à duração da disciplina, definiram-se ciclos curtos de execução da atividade e, mesmo que a realimentação estimulasse melhorias no processo, não houve tempo para novas versões de rodadas já executadas. Dificuldades adicionais tiveram sua origem na característica pioneira dessa experiência no contexto do curso e da disciplina, assim como no uso de um AVA e de editor wiki 
para parte significativa dos participantes. Quanto ao uso de editor colaborativo em outras atividades do curso, $86 \%$ dos respondentes da primeira turma (e 78\% da segunda) declararam-se motivados. Os discordantes ressaltaram que os problemas da plataforma, e o fato de não terem sido bem avaliados, reduzem a motivação.

Identificaram-se perdas de processo nas declarações de alguns participantes quanto ao fato de que outros grupos fizeram cópias do conteúdo considerado privativo (sucker effect). Vários movimentos de postagem demonstraram fragilidade de construção cognitiva derivada do corte/colagem dos textos de apoio. 0 histórico de intervenções revelou que participantes se limitaram a inserir o mínimo de material relativo à sua responsabilidade sem realizar ajustes globais, mesmo que alertados para o aspecto das ações colaborativas. Percebeu-se, igualmente pelas postagens, que, quanto mais intensa era a participação e a interferência de um líder do grupo, menor era o aporte de outros integrantes (indícios de social loafing e do efeito Ringelmann).

Em relação aos líderes, visualizou-se uma dinâmica pautada por intervenções de ajuste (supermáxima de relevância e categoria modo) mais próximas do proposto na escrita colaborativa e de autogestão da aprendizagem. A explicitação da pontuação diferenciada para esses no quadro de critérios de avaliação e a divulgação aberta das notas, rodada a rodada, possivelmente amenizaram o fenômeno de social loafing da atividade. Mudanças de comportamento a partir das recompensas revelaram que, após a atribuição de notas, houve desistência de participantes que receberam avaliações desfavoráveis nas primeiras rodadas. Na primeira turma, houve redução de esforço na última rodada após a publicação da nota da prova. Para alguns líderes, conforme depoimentos informais, a participação aumentou com o objetivo de manter/melhorar a própria nota e auxiliar os demais integrantes do grupo.

As categorias agregadas ao princípio cooperativo de Grice, ao serem transpostas para o discurso escrito, puderam ser validadas considerando-se o dimensionamento dos aportes cognitivos e o formato/consistência das postagens individuais. Todas as possibilidades de participação tiveram, assim como preconizado por Swan, Shen e Hiltz (2006), seu mérito apreciado na dimensão quantitativa (regularidade e número e extensão das contribuições), e na dimensão qualitativa (valor cognitivo da postagem e grau de novidade). Contudo, o editor wiki utilizado não reúne recursos suficientes para que se visualizem com clareza todas as intervenções nos textos. Tais características colocaram em xeque o uso dos pesos dos critérios de avaliação, fato notado pelos alunos quando de sua autoavaliação e avaliação do material elaborado pelos colegas, incluídas aí as percepções da intervenção do colega em sua postagem e dos resultados finais alcançados. Não foi possível recuperar evidências de mudanças cognitivas postagem a postagem, o que exigiriam recursos de análise de conteúdo, reconhecido como um procedimento trabalhoso, na melhor das circunstâncias (GARRISON, ANDERSON, ARCHER, 2001).

A aplicação dos critérios adaptados às categorias agregadas ao princípio cooperativo de Grice tampouco explicitou o grau de colaboração relativamente:

a) ao tipo de organização do trabalho no grupo e a divisão de tarefas;

b) ao fluxo de sugestões, críticas e mensagens entre os membros do grupo;

c) às intervenções elaboradas fora do editor wiki (incluindo as que foram possivelmente descartadas); e

d) às discussões, nos grupos, relativas às funcionalidades da ferramenta e as justificativas seu uso/não uso.

0 monitoramento de tais movimentos externos ao editor wiki (e ao próprio AVA) poderia auxiliar na verificação da existência (ou não) de mais perdas de processo e embasar propostas para futuros trabalhos na temática.

Por outro lado, o uso de um editor wiki apresenta avanços se comparado ao processo tradicional de produção de trabalho em grupos, ainda que exija investimento contínuo na sensibilização quanto à corresponsabilidade 
dos elementos do grupo e no domínio das funcionalidades da ferramenta.

Uma avaliação mais consistente e justa, assim como um melhor aproveitamento em exercícios que pressupõem e incentivam a escrita colaborativa em editores wiki, deve se apoiar em uma ferramenta que facilite a visualização e promova o monitoramento consistente das ações dos participantes, tais como as postagens individuais e as intervenções dos colegas, do professor e do tutor. A proposta de trabalho disponibilizada deve indicar, além do objetivo geral, o que se espera como ações colaborativas nos (e entre os grupos) e, idealmente, a discussão e defınição conjunta e negociada dos critérios de avaliação (e respectiva pontuação). Professor e tutor necessitam de um domínio extra da tecnologia envolvida e de rapidez na dissolução de conflitos intra e entre grupos e nos processos de realimentação.

Trentin (2008) destaca o papel crítico do controle de versões, da etiquetagem de conteúdo, dos comentários e dos links de hipertexto como funcionalidades sine qua non para um editor colaborativo de conteúdo (seja um editor wiki ou não). A autora defende que os grupos devem criar e explicitar suas regras de trabalho na forma de um planejamento que extrapole/ complete as orientações e os modelos/guias definidos pelo professor e tutor. Um consenso acerca do formato do conteúdo, da necessidade de links internos e externos ao texto, a divisão das tarefas, a indicação de responsabilidades de administração das páginas, e da definição de regras para modificações/intervenções/comentários, deve ser obtido e explicitado no âmbito do grupo. Desta forma, todos os envolvidos estarão, potencialmente, mais seguros e motivados quanto à sua participação na elaboração do resultado final do processo.

Considera-se, adicionalmente, que a proposta de trabalho colaborativo não é uma barreira per se, ainda que dificuldades técnicas desestimulem participantes. Um editor colaborativo que dificulte a integração imediata entre colaboradores acarretará contribuições estanques, o que não só diluirá o fluxo comunicativo consensual desejado, como incitará o uso de alternativas externas.

No que tange à sensibilização para a participação em comunidades de prática, por exemplo, Brodahl, Hadjerrouit e Hansen (2011) reforçam a paulatina exigência do uso da tecnologia a favor da interação e de objetivos comuns que dependem da (re)negociação de significados em determinado domínio profissional. Nesse sentido, reflexões conjuntas na construção de conteúdos - derivadas da análise de interferências de colegas em espaços virtuais colaborativos - auxiliam não apenas na autogestão do aprendizado, mas também no reposicionamento de papéis no processo de ensino-aprendizagem, os quais extrapolam as fronteiras do ambiente escolar/acadêmico.

\section{Referências}

ALVES, Lynn. Um olhar pedagógico das interfaces do moodle. In: ALVES, Lynn.; BARROS, Daniela; OKADA, Alexandra (Orgs.). Moodle: estratégias pedagógicas e estudo de caso. Salvador: Eduneb, 2009. p. 187-201. Disponível em: <http://www.moodle. ufba.br/file.php/1/Moodle_1911_web.pdf>. Acesso em: 15 mar. 2013.

BRODAHL, Cornelia; HADJERROUIT, Said; HANSEN, Nils Kristian. Collaborative writing with web 2.0 technologies: education students' perceptions. Journal of Information Technology Education Innovations in Practice, v. 10, p. 73-103, 2011. Disponível em: <http://jite.org/documents/Nol10/JITEv10IIPp073-103Brodahl948.pdf>. Acesso em: 16 dez. 2012.

CRUZ, Cláudia et al. Uma abordagem da avaliação online no ensino superior: e-portfólios em rede social. EDUSER: revista de educação, v. 2, n. 2, p. 3-27, 2010. Disponível em: <https://www.eduser.ipb.pt/index.php/eduser/article/viewFile/49/28 >. Acesso em: 16 dez. 2012.

DAMIANI, Magda Floriani. Entendendo o trabalho colaborativo em educação e revelando seus benefícios. Educar em Revista, n. 31 , p. 213-230, 2008. Disponível em: <http://dx.doi.org/10.1590/S0104-40602008000100013 >. Acesso em: 16 dez. 2012.

DAVIES, Bethan L. Grice's cooperative principle: meaning and rationality. Journal of Pragmatics, v. 39, p. 2308-2331, 2007. Disponível em: <http://dx.doi.org/10.1016/j.pragma.2007.09.002>. Acesso em: 16 dez. 2012. 
FERRAZ, Obdalia. Tecendo saberes na rede: o moodle como espaço significativo de letra e escrita. In: ALVES, Lynn; BARROS, Daniela; OKADA, Alexandra (Org.) Moodle: estratégias pedagógicas e estudo de caso. Salvador: Eduneb, 2009. p. 143-164. Disponível em: <http://www.moodle.ufba.br/file.php/1/Moodle_1911_web.pdf>. Acesso em: 15 mar. 2013.

FORMAN, Ellice Ann; LARREAMENDY-JOERNS, Jorge. Making explicit the implicit: classroom explanations and conversational implicatures. Mind, Culture, and Activity, v. 5, n. 2, p. 105-113, 1998. Disponível em: <http://dx.doi.org/10.1207/ s15327884mca0502_4>. Acesso em: 16 dez. 2012.

FORSYTH, Donelson R. Group dynamics. Belmont: Wadsworth Cengage Learning, 2010.

GARRISON, D. Randy; ANDERSON, Terry; ARCHER, Walter. Critical thinking, cognitive presence and computer conferencing in distance education. American Journal of Distance Education, v. 15, n. 1, p. 7-23, 2001. Disponível em: <http://cde.athabascau. ca/coi_site/documents/Garrison_Anderson_Archer_CogPres_Final.pdf>. Acesso em: 16 dez. 2012.

GRICE, Paul. Studies in the way of words. Cambridge: Harvard University Press, 1989.

HARKINS, Stephen H.; SZYMANSKI, Kate. Social loafing and group evaluation. Journal of Personality and Social Psychology, v. 56, n. 6, p. 934-941, 1989. Disponível em: <http://dx.doi.org/10.1037/0022-3514.56.6.934>. Acesso em: 16 dez. 2012.

HO, Chia-Huan; SWAN, Karen. Evaluating online conversation in an asynchronous learning environment: an application of Grice's cooperative principle. Internet and Higher Education, v. 10, p. 3-14, 2007. Disponível em: <http://dx.doi.org/10.1016/j. iheduc.2006.11.002>. Acesso em: 16 dez. 2012.

KARAU, Steven; WILLIAMS, Kipling. Social loafing: a meta-analytic review and theoretical integration. Journal of Personality and Social Psychology, v. 65, n. 4, p. 81-706, 1993. Disponível em: <http://myweb.unomaha.edu/ mcortese/karau\%20williams\%20 1993.pdf>. Acesso em: 16 dez. 2012.

PELZ, Bill. (My) Three principle of effective online pedagogy. Journal of Asynchronous Learning Networks, v. 8, n. 3, p. 33-46, 2004. Disponível em: <https://wiki.queensu.ca/download/attachments/35193389/BillPelz-JALNv8n3.pdf?version=1\&modificatio nDate $=1233004869000>$. Acesso em: 16 dez. 2012.

PIEZON, Sherry L.; FERREE, Willian. D. Perceptions of social loafing in online learning groups: a study of public university and U.S. Naval War College students. International Review of Research in Open and Distance Learning, v. 9, n. 2, p. 1-17, 2008. Disponível em: <http://www.irrodl.org/index.php/irrodl/article/view/484/1034>. Acesso em: 16 dez. 2012.

PRATA, David Nadler. Estratégias para o desenvolvimento de um framework de avaliação da aprendizagem à distância. In: SIMPÓSIO BRASILEIRO DE INFORMÁTICA NA EDUCAÇÃO, 16., Rio de Janeiro, 2003. Anais... Rio de Janeiro: NCE - IM/UFRJ, 2003. Disponível em: <http://www.nce.ufrj.br/sbie2003/publicacoes/paper16.pdf>. Acesso em: 16 dez. 2012.

SKAF-MOLLI, Hala et. al. New work modes for collaborative writing. In: INTERNATIONAL CONFERENCE ON ENTERPRISE INFORMATION SYSTEMS AND WEB TECHNOLOGIES, Funchal, 2007. Anais.... Funchal: Institute for Systems and Technologies of Information, Control and Communication, 2007. Disponível em: <http://hal.inria.fr/docs/00/12/92/22/PDF/eiswt142.pdf>. Acesso em: 16 dez. 2012.

SWAN, Karen; SHEN, Jia; HILTZ, Starr Roxanne. Assessment and collaboration in online learning. Journal of Asynchronous Learning Networks, v. 10, n. 1, p. 45-62, 2006. Disponível em: <http://www-new.kent.edu/ehhs/dl/upload/assessment-andcollaboration.pdf>. Acesso em: 16 dez. 2012.

TRENTIN, Guglielmo. Using a wiki to evaluate individual contribution to a collaborative learning project. Journal of Computer Assisted Learning, v. 25, n. 1, p. 43-55, 2008. Disponível em: <http://dx.doi.org/10.1111/j.1365-2729.2008.00276.x>. Acesso em: 16 dez. 2012.

VALENTE, Luís; MOREIRA, Paulo; DIAS, Paulo. Moodle: moda, mania ou inovação na formação? In: ALVES, Lynn; BARROS, Daniela; OKADA, Alexandra (Org.). Moodle: estratégias pedagógicas e estudo de caso. Salvador: Eduneb, 2009. p. 35-54. Disponível em: <http://www.moodle.ufba.br/file.php/1/Moodle_1911_web.pdf>. Acesso em: 15 mar. 2013.

Recebido em: 05.07.2012.

Aprovado em: 17.03.2013.

Patricia Zeni Marchiori é mestre em Ciência da Informação pela Universidade Federal do Rio de Janeiro e doutora em Ciências da Comunicação pela Universidade de São Paulo. É professora titular do Departamento de Ciência e Gestão da Informação da Universidade Federal do Paraná.

Ana Carolina Greef é mestre em Ciência, Gestão e Tecnologia da Informação pela Universidade Federal do Paraná e pesquisadora nas áreas de fluxos de informação e Lean Office aplicadas a espaços de ensino-aprendizagem e escritórios. 